\title{
Single-Parent Families and Adolescent Crime: Unpacking the Role of Parental Separation, Parental Decease, and Being Born to a Single-Parent Family
}

\author{
Janique Kroese $\mathrm{K}^{1,2}$ (D) Wim Bernasco ${ }^{1,2}$ (D) Aart C. Liefbroer ${ }^{3,4,5}$ - \\ Jan Rouwendal ${ }^{1,6}$ (i)
}

Received: 5 March 2021 / Revised: 22 October 2021 / Accepted: 24 October 2021 /

Published online: 17 January 2022

(C) The Author(s) 2022

\begin{abstract}
Addressing a gap in the extant literature on single-parent families and juvenile delinquency, we distinguish between different types of single-parent families. Using Dutch population register data on nearly 1.3 million children, we performed logistic regressions to assess the relation between growing up in a single-parent family before age 12 and the likelihood to engage in juvenile delinquency during adolescence. Our findings suggest that the likelihood of juvenile delinquency increases (1) when children are born to a single parent, followed by children with separated parents and children experiencing parental death, compared to children growing up with both biological parents; (2) when the single-parent family started at a younger age; and (3) when children grow up with only a biological mother, for both sons and daughters, compared to only a biological father. The relationship between growing up in single-parent families and juvenile delinquency is much more complex than often assumed. Future research should pay more attention to diversity in the composition of single-parent families.
\end{abstract}

Keywords Single-parent families $\cdot$ Separation $\cdot$ Parental decease $\cdot$ Born to a single parent $\cdot$ Juvenile delinquency $\cdot$ Adolescence

Although most children in Western countries are raised by both of their biological parents, a large minority grows up without their biological father or biological

Janique Kroese

j.h.kroese@vu.nl

Extended author information available on the last page of the article 
mother. Typically, this is because the biological parents have stopped living together or never lived together, or because one of them passed away. Here, we refer to these situations as single-parent families ${ }^{1}$. At any given time, this holds for $15 \%$ of the families with children in the European Union (Eurostat, 2019) and for 23\% of the families in the USA (Pew Research Center, 2019).

A family environment that includes both biological parents is often seen as an important resource for a successful transition through adolescence (Amato, 2001). Therefore, it is important to investigate the consequences of growing up in a singleparent family. One of the negative consequences that have been studied extensively is involvement in criminal behavior as an adolescent. It is well-established in the empirical literature (e.g., Amato, 2001; Kroese et al., 2021) as well as hypothesized by several criminological theories (e.g., general strain theory and social control theory; Agnew, 2006; Hirschi, 1969) that growing up in a single-parent family and juvenile delinquency are related. This is of high societal relevance, not only because the victims of delinquency suffer injuries, losses, and other harms (Campagna \& Zaykowski, 2020), but also because criminal behavior is associated with negative life outcomes to the juvenile committing delinquent acts, such as a lower income (Apel \& Sweeten, 2010), health problems (Massoglia, 2008), and a lower well-being and a higher probability of criminal involvement as an adult (Gilman et al., 2015).

In this paper, we attempt to unpack the relationship between criminal behavior of adolescents and growing up in a single-parent family by distinguishing differential characteristics of single-parent families in the Netherlands. More specifically, we differentiate on the basis of the type of single-parent family the age of the child(ren) when the single-parent family started, and the sex of the biological parent the children grew up with. The reasoning behind our investigation of these characteristics is the change in increasingly tolerant attitudes and norms regarding single-parent families in Western countries (Kreidl et al., 2017), such as the Netherlands. First, parental separation and single mothers by choice become a more common experience (CBS, 2018, 2019a). Second, from 1995 onwards, divorcing parents could request joint legal custody of their children instead of the default of sole custody, and in 1998, joint legal custody became the default option (Staatsblad, 1995, 1997). However, it was still considered best for young children to spend a lot of time with their primary caregiver (e.g., only from age 5 onwards, children were recommended to stay overnight at the other parent's house). This has changed considerably over the years for younger children after the promotion of shared parenting (Richtlijnen Jeugdhulp, 2020). Third, equality between men and women in Western societies is increasing. For instance, Dutch women are becoming more financially independent, which results in a lower poverty risk for women after a separation (i.e., the poverty risk for women after a separation reduced from $25 \%$ in 2012 to $17 \%$ in 2017; CBS, 2020). The current study thus adds to the existing literature by examining the relationship between criminal behavior during adolescence and (1) how single-parent

\footnotetext{
1 No official term exists for children who do not grow up in a household with two biological parents. Many terms have been used in the literature. We chose to use the term "single-parent family," but we are aware of the sensitivities regarding this type of wording.
} 
families were constituted (by parental separation, parental decease, or being born to a single parent), (2) the age of the children when the different types of single-parent families were constituted, and (3) the distinction between children growing up with their biological father or biological mother in the different types of single-parent families. These three aspects have rarely been examined in prior research due to data limitations (e.g., due to a low number of single-father families; Demuth \& Brown, 2004). In this study, longitudinal population register data were used that include the complete population of The Netherlands born in 1993-1999. Therefore, this dataset is large enough to allow authoritative answers to our research questions.

\section{Constitution of Single-Parent Families}

A potentially important omission in most previous studies about the role of singleparent families in the onset of juvenile delinquency is that they have not considered the constituting event that generates a single-parent family (Kroese et al., 2021). Three types of single-parent families with children residing with one biological parent can be distinguished based on whether the family was generated by (1) parental separation, (2) the death of a parent, or (3) the child being raised by a single parent since birth. Although these experiences all result in single-parent families, they are associated with different processes and may have differential consequences for delinquent behavior.

The family crisis model focuses on the processes involved in family disruptions (see Mack et al., 2007). This model suggests that psychological distress, emotional resentment, and social tension are more often related to parental separation than parental death. Moreover, experiencing a crisis event often increases the likelihood for children to display antisocial behavior. Therefore, children who experience a parental separation may feel resentment toward their parents that will, in consequence, increase the likelihood of a reduced family attachment and more engagement in juvenile delinquency. In contrast, parental death is a traumatic event that produces anxiety, emotional distress, and depression, but does not usually involve the same level of emotional resentment as in separated families. Because children born to a single parent did not experience a family disruption crisis, these children are expected to display less criminal behavior than children in the other two types of single-parent families. However, since several criminological theories hypothesized that growing up in a single-parent family and juvenile delinquency are related, we do expect to find a higher likelihood to engage in criminal behavior for children born to a single parent than children living with both biological parents (e.g., social control theory (Hirschi, 1969) suggests that children in single-parent families might show more delinquency because they possibly have a less strong attachment to one or both parents). Therefore, based on the family crisis model combined with the other theories about the consequences of single-parent families, we hypothesize that (1) growing up in a single-parent family increases the likelihood to engage in juvenile delinquency compared to growing up with two biological parents (H1a), and, more specifically, (2) of those children growing up in a single-parent family, children experiencing a parental separation show the highest level of juvenile 
delinquency, followed by children experiencing a parental death, and children born to a single parent show the lowest level of juvenile delinquency (H1b).

Several empirical studies investigated the effects of parental separation and parental death. Most of the studies on parental disruption (see Kroese et al., 2021) showed that children with separated parents were more likely to engage in delinquent behavior than children living with both biological parents (e.g., Spohn \& Kurtz, 2011; Vanassche et al., 2014) and the remaining studies showed no differences between these families. A study by Berg et al. (2019) on the effects of experiencing a parental death during childhood showed an increased risk of violent crime in adolescents. A study by Juby and Farrington (2001) found that families disrupted by separation were more criminogenic than families disrupted by parental death when looking at reports on juvenile convictions. However, no differences between these two types of single-parent families were found when delinquency was self-reported. We know of no studies that specifically examined the effect of being born into a single-parent family.

\section{Age of the Children at the Time of the Constituting Event}

Except for children born to a single parent, children can experience the start of a single-parent family at any age. However, it is not clear yet to what extent the age of the children at the start of the family disruption influences the relation between living in single-parent families and juvenile delinquency.

Bowlby's attachment theory (Ainsworth \& Bowlby, 1991) suggests that attachment derives from the biological preparation of both child and parents to respond to each other's behaviors in such a way that parents provide the child with care and protection. The loss of a biological parent can lead to weaker attachment and/or the development of insecure attachment, as a key relationship is ruptured. Bowlby proposes that disruptions at younger ages (especially during the first 5 years of life) have more negative effects than disruptions at a later age, since attachment is formed early in life. Research in several theoretical areas showed that attachment between parents and their child makes a difference in the adolescent's participation in delinquency (Sogar, 2017). Based on Bowlby's attachment theory, we hypothesize that a lower age of the children during the constitution of the single-parent family increases the likelihood to engage in juvenile delinquency (H2a). Moreover, when we combine Bowlby's attachment theory and the family crisis model, we hypothesize that children experiencing a parental separation at a younger age show a higher level of juvenile delinquency compared to children experiencing a parental death at a younger age $(\mathrm{H} 2 \mathrm{~b})$.

The existing literature mostly confirms the expected relation between experiencing the constitution of a single-parent family at a younger age and a higher level of juvenile delinquency. Juby and Farrington (2001) reported a higher risk of juvenile delinquency when the parental disruption occurred from 0 to 4 years old, compared to when it occurred from 5 to 9 years old (although the risk again increased between ages 10 and 14). Price and Kunz (2003) conducted a meta-analysis about parental divorce; when studies used samples of younger children in comparison with studies 
with older children, they found larger criminogenic effect sizes. Berg et al. (2019) did not find statistically significant differences between the age categories with regard to the child's age at the time of death of their parent.

\section{Sex of the Biological Parents}

A number of contradictory ideas about the effects of the sex of the biological parent on juvenile delinquency have been constructed, leading us to formulate three (partially competing) hypotheses.

Bowlby's attachment theory (Ainsworth \& Bowlby, 1991) predicts that separation from the mother is more harmful than separation from the father. Bowlby believed that it is crucial that a child experiences a warm and loving relationship with a mother figure. The maternal hypothesis is very similar, as it states that living with a single mother should be expected to cause a lower level of delinquency than living with a single father, because the mother is better able to exercise a more effective control of the child (see Eitle, 2006). Based on Bowlby's attachment theory and the maternal hypothesis, we hypothesize that growing up with only a biological father in a single-parent family increases the likelihood to engage in juvenile delinquency in comparison with growing up with only a biological mother (H3a). Moreover, when we combine these theoretical ideas and the family crisis model, we hypothesize that children experiencing a parental separation growing up with only a biological father show the highest level of juvenile delinquency, and children born to a single parent growing up with only a biological mother show the lowest level of juvenile delinquency (H3b).

In contrast to Bowlby's attachment theory, the equality hypothesis suggests that there is little difference between the single-mother and single-father families with respect to the criminal behavior of the children, because the equality between men and women in Western societies is increasing (see Eitle, 2006). Based on the equality hypothesis, we hypothesize that the sex of the biological parent in a single-parent family does not affect the likelihood to engage in juvenile delinquency ( $\mathrm{H} 3 \mathrm{c}$ ).

The same-sex hypothesis states that the biological parent who is of the same sex as the child is the more effective role model for the child (see Eitle, 2006), suggesting that the father is a better role model for the son and the mother is a better role model for the daughter. Based on the same-sex hypothesis, we hypothesize that children growing up in same-sex parent-child dyads are less likely to engage in juvenile delinquency than children growing up in opposite-sex parent-child dyads, meaning that sons growing up with biological mothers and daughters growing up with biological fathers have an increased likelihood to engage in juvenile delinquency compared to sons growing up with biological fathers and daughters growing up with biological mothers (H3d).

Congruent with these contradicting theories, empirical studies show conflicting results as well. A number of studies found support for the same-sex hypothesis. Ram and Hou (2005) and Eitle (2006) found that living in a single-mother family increases the level of crime for male adolescents compared to female adolescents. Vanassche et al. (2014) noted that growing up in a family with the same-sex parent 
reduces the level of delinquency of the children. However, Juby and Farrington (2001) found that boys were significantly more likely to self-report delinquency and have arrest records when growing up in a single-father family compared to a single-mother family. Moreover, Demuth and Brown (2004) found that mean levels of delinquency are highest among adolescents residing in single-father families, independent of the sex of the child.

\section{Other Factors}

In studying the relationship between family structure and delinquency, several factors need to be controlled for. The first factor is parental crime, because several studies find a positive correlation between parental crime and juvenile delinquency (e.g., Besemer et al., 2017). The second factor is the sex of the child, because boys have typically been responsible for the majority of youth crimes (Peterson et al., 2007; Messerschmidt, 2013). The third factor is the income of the household. There are contradictory theories and results regarding household income. General strain theory (Agnew, 2006) suggests that delinquent behavior is affected by the strain caused by a relative lack of resources, which is more common in single-parent households. The stigmatization hypothesis states that single-parent families were normative in low-income neighborhoods, but not in high-income neighborhoods (Becker, 1963), resulting in a higher likelihood for children from single-parent families in highincome neighborhoods to engage in criminal behavior. The economic strain model focuses on how lack of resources may mediate the effects that single-parent families have on adolescent criminal behavior (see Sogar, 2017). Some studies found that single-parent families were more strongly associated with crime in low-income families (e.g., Hay et al., 2006), yet other studies reported only a trivial effect of income on the relation between single-parent families and juvenile delinquency (e.g., Kierkus $\&$ Bear, 2003). The fourth factor is the birth year of the children to control for birth cohort effects, since from the 1990s onwards, in many Western countries, the level of crime started to decrease (Farrell et al., 2014). The fifth factor is whether or not the single parent started to live together with a new partner. According to social control theory (Hirschi, 1969), the arrival of a stepparent should act as a protective factor, because two parents are available again to care for the children. However, according to general strain theory (Agnew, 2006), having a stepparent in the household might raise the level of family discord and lead to a greater risk of delinquency. Most empirical studies find results in accordance with general strain theory, showing an increased likelihood of juvenile delinquency after the entry of a stepparent into the family (e.g., Brown, 2006; Vanassche et al., 2014). The sixth factor is the country of birth of the children's biological parents, because several studies showed incongruent results regarding the relation between ethnic minority youths and crime rates (e.g., Rima et al., 2019). The seventh factor is the age of the biological mother at the birth of the child, as children born to younger mothers compared to children born to older mothers are more prone to general delinquency, violence, and arrest (e.g., Pogarsky et al., 2003). 


\section{Method}

\section{Data and Study Population}

For the present study, seven complete birth cohorts of individuals born in the period 1993-1999 were selected. These seven birth cohorts were chosen to maximize the number of observed adolescents, since all required microdata sets were available for these birth cohorts. In particular, the data include crime data for each individual between ages 12 and 18. Individuals were excluded from the analysis if they were stillborn, if they passed away before the age of 19 , or if they were born outside the Netherlands. If individuals emigrated before the age of 19, they were also removed from the data. The reason for this removal is that the crime data from the Dutch National Police only apply to crimes perpetrated in the Netherlands and does not include crimes perpetrated abroad. This resulted in a sample of 1,296,652 children.

The data used in this study were constructed by combining various register-based datasets accessible via Statistics Netherlands (Centraal Bureau voor de Statistiek). ${ }^{2}$ These datasets contain (generally longitudinal) individual or household level data on the entire registered population of the Netherlands. We used the anonymized personal identifiers constructed by Statistics Netherlands to link the microdata sets. The datasets contain information from different sources. Basic demographic and administrative information about individuals and their family members, such as their date of birth and death, sex, registered address, and marital status, were extracted from the population register (Basisregistratie Personen). The population register does not only include current information, but also historical information, such as former addresses and previous marriage partners.

For the present study, it should be noted that at any point in time, individuals can only be registered at a single address. Therefore, the registered address may not always have been the children's place of full-time residence, especially for children of separated parents. Often this registered address coincided with the address where they spent most of their time. However, for children of separated parents in 50/50 custody arrangements, the registered address is the place where they spent only half of their time. Based on an in-depth investigation of the validity of the registered home addresses of children of separated parents, Van der Wiel and Kooiman (2019) concluded that, in general, the registered address of children of separated parents adequately represents where children live and sleep. However, they also noted that a small number of children are registered with their father, yet actually live with their biological mother or live in a shared custody arrangement with both biological parents.

Information about household income, juvenile delinquency, and parental crime in the microdata was derived from other sources. Information on household income was based on data from The Dutch Tax and Customs Administration (Belastingdienst) from 2003 to 2010. The Dutch National Police provided data about juvenile

\footnotetext{
${ }^{2}$ Under certain conditions, these microdata sets are accessible for statistical and scientific research. For further information: microdata@cbs.nl.
} 
delinquency from 2005 to 2017 by means of the Basic Facility for Law Enforcement (Basisvoorziening Handhaving $[\mathrm{BVH}]$ ) and data about parental crime from 1996 to 2014 by means of the Police Offenders Identification System (Herkenningsdienst Systeem [HKS]). The HKS was dismantled in 2014. The BVH replaced the HKS, and it comprises a more elaborate list of offenses than the HKS system (see Table 1A for an overview of the types of crime in both datasets). Both datasets contain suspects of all ages who have been charged with a serious offense eligible for prosecution. This means that people received a "procès-verbal," an official report drawn up by a police officer about a crime that has occurred. Although the dataset thus does not only contain data about delinquents who were convicted, over $90 \%$ of the people in the dataset are estimated to receive a transaction (e.g., a fine) or to be charged and found guilty by a judge (Besjes \& Van Gaalen, 2008).

\section{Measures}

Family structure is a key concept in our analysis. It is operationalized by two variables, i.e., "single-parent family" and "type of single-parent family."

Single-Parent Family The first variable representing family structure is whether or not the individual always lived with both biological parents ${ }^{3}$ between birth and age 12. Whether a child lived with both biological parents was measured at the start of each calendar year by verifying that the child's registered address was the same as the registered address of both biological parents. We did not distinguish between married and cohabiting parents. Single-parent families include children living with only one biological parent (possibly in combination with other adults, such as a stepparent or grandparent). Children living without any biological parents were excluded from the analyses $(N=6,792)$.

Type of Single-Parent Family Next to differentiating between children living with both biological parents and children living in single-parent families, we also make a distinction between different types of single-parent families, based on the event that resulted in the family becoming single-parent. This means that another key independent variable is the type of family the child lives in before age 12. In the first single-parent family, children live together with only one biological parent after their parents got separated. When one biological parent got a different registered address than the other biological parent and their offspring, this was coded as a parental separation. It is possible that the biological parents reunited after a (couple of) year(s), yet this child will still be categorized as having experienced a parental separation. In most cases, this constitutes families who experienced a parental break-up

\footnotetext{
3 We are aware of the fact that data of Statistics Netherlands only contains information on legal parenthood. However, research shows that for over $99 \%$ of the children, their parents are their legal as well as their biological parents (e.g., Larmuseau et al., 2017). In the Netherlands, it is possible for two people of the same sex to both become the legal parents of a child. In our analyses, we will not make a distinction between same-sex couples and opposite-sex couples.
} 
of a marriage or a cohabiting union. The second single-parent family includes children who live with one biological parent because the other biological parent has deceased. In the third single-parent family, children live together with only one biological parent throughout childhood, because they were born to a single parent (for instance, because one of the biological parents passed away before the child was born or because the biological parents never lived together).

To construct the variable "type of single-parent family," we first checked whether the children were born to a single parent, and assigned these children to the third category of single-parent families "living in a single-parent family due to being born to a single parent." If this was not the case, we checked whether one of their parents had passed away between birth and age 11, and assigned these children to the second category of single-parent families "living in a single-parent family due to a parental death." In case this did not happen, we checked whether their biological parents had been separated between birth and age 11, and assigned these children to the first category of single-parent families "living in a single-parent family due to a parental separation."

Juvenile Delinquency The dependent variable was based on recorded criminal behavior of the adolescents as registered by the Dutch National Police (see Table 1A for an overview of the items about juvenile delinquency). It was defined as a dichotomous variable indicating whether or not the adolescent has been a suspect of any criminal act (i.e., legally prosecuted) between the ages of 12 and 18, independent of the number of crimes or the severity of the crime(s). ${ }^{4}$

Age at Family Disruption The age of the child when the single-parent family started was taken into account as an independent variable. For children born to a single parent, the value of this variable was 0 by definition. If the biological parents separate more than once, thus the child having two or more different ages of parental separation, only the first age of the child will be used in our analyses.

Sex of the Biological Parent The sex of the biological parent the adolescent lived with during the year(s) of living in a single-parent family was also included as an independent variable. The dataset contains an indicator of sex, and not gender identity, which means that only a binary indicator is available. To be able to test hypothesis $3 \mathrm{~d}$, the sex of the biological parent was cross-classified with the sex of the child.

Controls We also included a set of control variables. First, we controlled for criminal behavior committed by the biological parents (see Table 1A for an overview of the items about parental crime, ranging from road traffic offenses to violent property crimes). We defined this variable as whether none of the biological parents, one of the biological parents, or two of the biological parents have been a suspect

\footnotetext{
4 The variables indicating the criminal behavior of the children and their parents were dichotomized, because they were highly right-skewed. Most people were never a suspect of a crime, and those who were a suspect often only were a suspect of a crime only once.
} 
of a criminal act before the child turned 12 years old, independent of the number of crimes and the severity of the crime(s). Second, to account for the universally observed sex difference in delinquency, we controlled for the sex of the child. Third, we controlled for the annual income of the household in which the child lived at age 12. In order to correct for the impact of household size and composition on household income, we made use of an equivalence scale (CBS, 2019b), by taking into consideration (1) the size of the household and (2) whether the members were adults (18 years and older) or children. Moreover, to prevent households showing a negative household income being excluded from the sample as a consequence of using the natural logarithm function for household income, an additional dummy variable was included for negative household incomes. Fourth, we controlled for the birth cohort of the children consisting of the years 1993 until 1999, to control for unmeasured period effects in crime or in crime reporting practices. Fifth, we controlled for the possibility that a biological parent in a single-parent family got a new partner, by means of repartnering in the form of a cohabiting union or remarriage. We defined this variable as whether none of the biological parents, one of the biological parents, or two of the biological parents had a new partner before the child turned 12 years of age. Sixth, we controlled for the country of birth of the biological parents (based on a distinction made by Statistics Netherlands; CBS, 2021), categorized as "both biological parents were born in The Netherlands," "one or two biological parents were born abroad in a Western country" (i.e., countries in Europe (excluding Turkey), North America, and Oceania, as well as the countries Indonesia and Japan), and "one or two biological parents were born in a non-Western country" (countries in Africa, Latin America, and Asia, as well as the country Turkey). If a child has one parent who was born in a Western county and one parent who was born in a non-Western county, this child was categorized as "one or two biological parents were born in a non-Western country." Seventh, we controlled for the age of the biological mother when the child was born, consisting of the categories "until age 19," "between age 20 and 29," "between age 30 and 39," and "40 years and older." To prevent multicollinearity, the age of the biological father was not included because it very strongly correlates with the age of the mother.

\section{Analyses}

Data management, record linkage, and analyses were executed on the secure server of Statistics Netherlands with STATA, version 15.0. Since the dependent variable is a dichotomous measure (i.e., whether or not the child has conducted juvenile delinquency between 12 and 18 years old), logistic regression analyses were performed. All analyses included the control variables mentioned above (see the Appendix for the complete tables including the control variables). Because the sample includes multiple siblings from the same families, these siblings have common unmeasured household characteristics. To correct for this violation of the independence assumption, we calculated robust standard errors that correct for common household-membership. 


\section{Results}

\section{Descriptive Statistics}

A total of 1,296,652 children were included in the analyses. Of these children, $77.08 \%$ grew up living with both biological parents, $14.47 \%$ experienced a parental separation, $1.11 \%$ experienced a parental death, and $7.33 \%$ were born to a single parent (see Table 1 for the descriptive statistics of each variable for the different types of families).

\section{Growing Up in (the Different) Single-Parent Families}

First, a logistic regression model was estimated to determine the relation between growing up living with both biological parents or living in a single-parent family and becoming a suspect of juvenile delinquency. The results, reported in Table 2, demonstrate that having lived with one biological parent before age 12 (compared to having lived with two biological parents before age 12) significantly increased the odds that the child became a suspect of delinquent behavior during adolescence (OR $=1.70,95 \% \mathrm{CI}[1.67,1.73])$. This means that hypothesis H1a is confirmed, because growing up in a single-parent family increased the likelihood to engage in juvenile delinquency compared to growing up with two biological parents.

Next, we estimated a model in which the three types of single-parent family categories were included separately and contrasted with children living with both biological parents. The results (see Table 2) show that having separated parents before age 12, having one deceased biological parent before age 12, or being born to a single parent (compared to having lived with two biological parents before age 12) all significantly increased the odds that the child became a suspect of delinquent behavior. Being born to a single parent showed the largest effects $(\mathrm{OR}=1.91,95 \%$ CI $[1.86,1.96])$, followed by having separated parents $(\mathrm{OR}=1.64,95 \%$ CI $[1.61$, 1.67]) and having one deceased biological parent before age 12 (OR $=1.62,95 \%$ CI $[1.54,1.70])$. Being born to a single parent also significantly increased the odds that the child became a suspect of delinquent behavior compared to having separated parents before age $12(\mathrm{OR}=1.17,95 \% \mathrm{CI}[1.14,1.19])$ or having one deceased biological parent before age $12(\mathrm{OR}=1.18,95 \% \mathrm{CI}[1.12,1.24])$. Having separated parents before age 12 did not significantly increase the odds that the child became a suspect of delinquent behavior compared to having one deceased biological parent before age $12(\mathrm{OR}=1.01,95 \% \mathrm{CI}[0.96,1.07])$. Thus, hypothesis H1b is not confirmed, because among children growing up in a single-parent family, children experiencing a parental separation before age 12 did not show the highest likelihood to engage in juvenile delinquency and children born to a single parent did not show the lowest likelihood to engage in juvenile delinquency. Instead, children born to a single parent showed the highest likelihood to engage in delinquency and both children experiencing a parental separation before age 12 and children having one deceased biological parent before age 12 showed the lowest likelihood. 


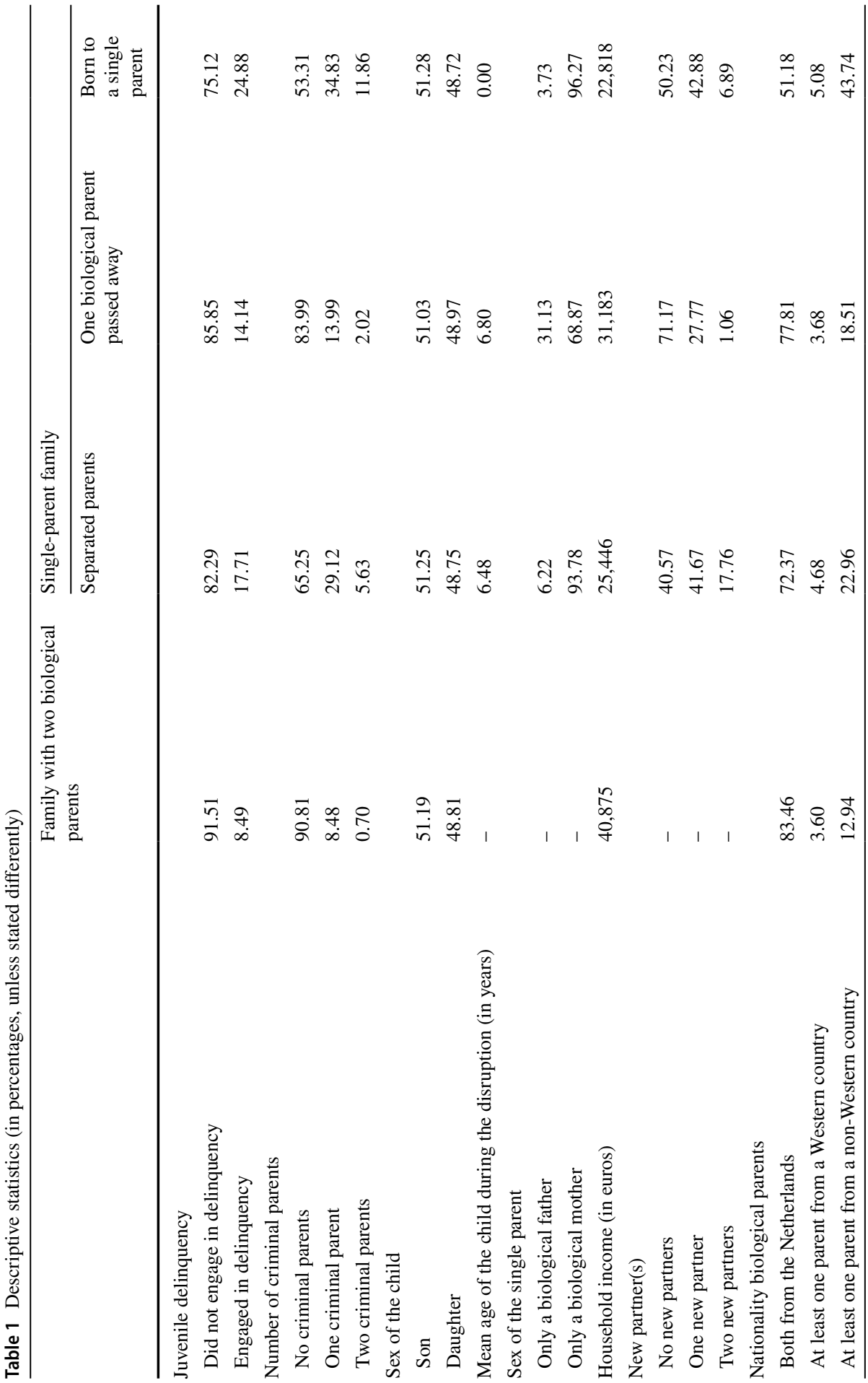







Table 2 Parameter estimates of a logistic regression model with juvenile delinquency as dependent variable and type of family (H1a) and the different types of single-parent family (H1b) as main independent variable $(N=1,295,683)$

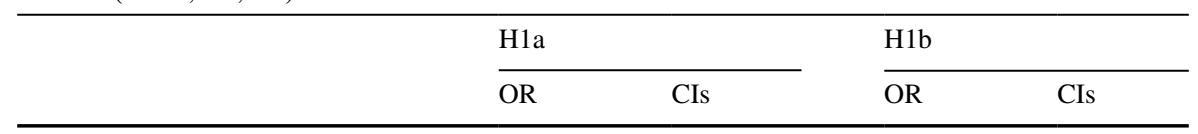

Type of family (reference category = Family with two biological parents)

Single-parent family $\quad 1.70 * * * \quad[1.67,1.73]$

Type of single-parent family (reference category = Family with two biological parents)

\begin{tabular}{lll} 
Separated parents & $1.64 * * *$ & {$[1.61,1.67]$} \\
One biological parent passed away & $1.62 * * *$ & {$[1.54,1.70]$} \\
Born to a single parent & $1.91 * * *$ & {$[1.86,1.96]$} \\
\hline
\end{tabular}

$* p<0.05 ; * * p<0.01 ; * * * p<0.001$. See Appendix for all tables containing the results including the control variables

Fig. 1 Age of the children when the (different types of) singleparent families were constituted and juvenile delinquency (in odds-ratios, $N=1,295,681$, reference category $=$ children living with both biological parents). Two children were omitted from the analysis, because the category "deceased parent" at age 1 only comprised of two children. See Appendix for all tables containing the results including the control variables

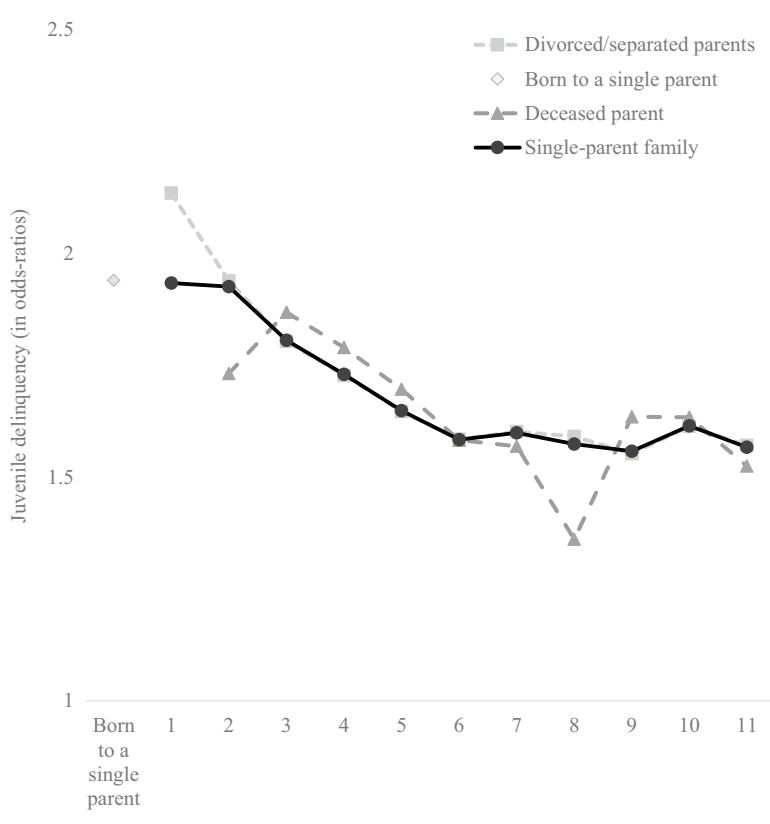

\section{Age of the Children During the Disruption}

A logistic regression model was estimated to establish the relation between the age of the children when the single-parent family was constituted and juvenile delinquency, in comparison with children living with both biological parents. As shown in Fig. 1, the higher the age of the children at the start of the single-parent family, the lower the likelihood that they became a suspect of delinquent behavior. The decreasing odds started to stabilize from age 6 onwards, meaning that there is little difference between children experiencing a disruption at age 6 or at age 11. These 
results imply that hypothesis $\mathrm{H} 2 \mathrm{a}$ is confirmed, because a lower age of the children during the constitution of the single-parent family increased the likelihood to engage in juvenile delinquency.

Another logistic regression model was estimated to investigate the relation between the age of the children when the different single-parent families were constituted and juvenile delinquency, in comparison with children living with both biological parents (see Fig. 1). Age 0 represents the children born to a single parent, and these children show a higher likelihood to become a suspect of delinquent behavior (OR $=1.94,95 \%$ CI $[1.89,1.99])$ than children living with both biological parents. Both the children experiencing a parental separation and the children with one deceased biological parent show a lower likelihood to become a suspect of delinquent behavior when the children are older at the start of the single-parent family. We did not find statistically significant differences between children experiencing a parental separation and the children with one deceased biological parent at the different age categories. These results do not confirm hypothesis $\mathrm{H} 2 \mathrm{~b}$, because both a lower age of the children when their parents separated and a lower age of the children when one of the parents passed away increased the likelihood to engage in juvenile delinquency.

\section{Sex of the Biological Parent in Single-Parent Families}

In the next logistic regression, we investigated the relation between the sex of the biological parent in the single-parent family and juvenile delinquency, and compared this to children living with both biological parents (see Table 3). Growing up with only a biological mother $(\mathrm{OR}=1.73,95 \%$ CI $[1.69,1.76])$ or only a biological father $(\mathrm{OR}=1.50,95 \% \mathrm{CI}[1.44,1.57])$ significantly increased the chance that the child became a suspect of delinquent behavior compared to children growing up with both biological parents. Growing up with a biological mother compared to growing up with a biological father significantly increased the chance that the child became a suspect of delinquent behavior ( $\mathrm{OR}=1.15,95 \% \mathrm{CI}[1.10,1.20]$ ). Based on these results, both hypothesis $\mathrm{H} 3 \mathrm{a}$ and hypothesis $\mathrm{H} 3 \mathrm{c}$ cannot be confirmed, because growing up with only a biological father in comparison with growing up with only a biological mother did not increase the likelihood to engage in juvenile delinquency $(\mathrm{H} 3 \mathrm{a})$, and we did not find differences in the results because of the sex of the biological parents (H3c). Instead, we found an increased likelihood to become a suspect of delinquent acts among children growing up with only a biological mother compared to growing up with only a biological father.

Another logistic regression was performed to establish the relation between the sex of the biological parent in combination with the type of single-parent family and juvenile delinquency, and again compared this to children living with both biological parents (see Table 3). Growing up with only a biological mother compared to a biological father when the child was born to a single parent $(\mathrm{OR}=1.51,95 \%$ CI $[1.36,1.67])$ significantly increased the chance that the child became a suspect of delinquent behavior. We did not find statistically significant differences between growing up with only a biological mother or a biological father after a separation 
凶্র

仓ิ

$\overbrace{\substack{1\\}}^{1}$

$\gtrsim \|$

茎

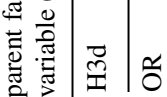

i

:

$\Xi$

产.

Ð

पे

函

宅:

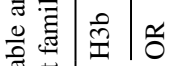



次

है

产

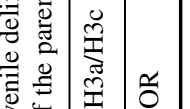

要

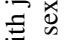

3 可

$\bar{\square}$

กิ

ㅇำ

.

总

늘

कृ

은

항

离

苟离

氜

: $\Xi$

类

$\sim$ ڤี

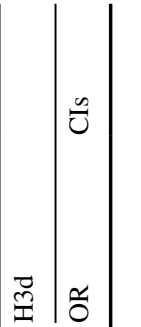

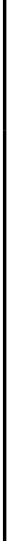

$\tilde{u}$

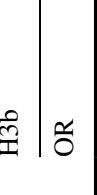

$\mid$



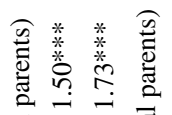

형ㅎㅎ

- $-\dot{i}-i$



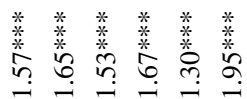

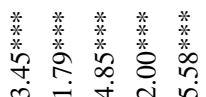

$\bar{\varpi} \Xi \varpi \Xi$

i $-i$ is

ले 8े हैं

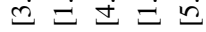

m. 앙

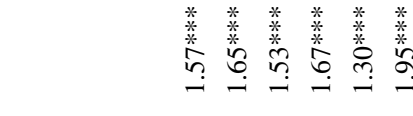

in

f.

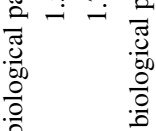

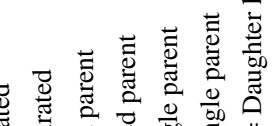

产

के छ

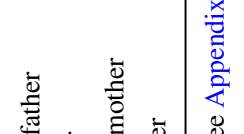

节矛过



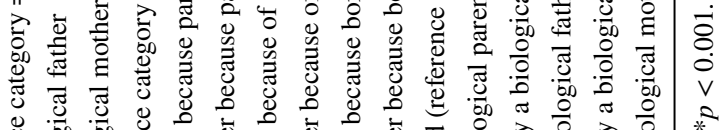

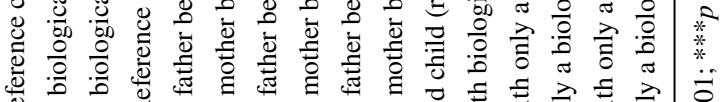

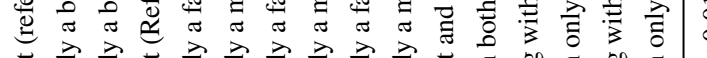

矛

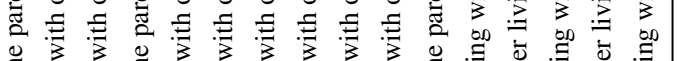

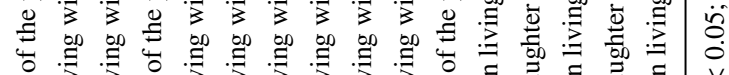


$(\mathrm{OR}=1.05,95 \% \mathrm{CI}[1.00,1.11])$, and growing up with only a biological mother or a biological father when one of the parents passed away $(\mathrm{OR}=1.09,95 \%$ CI $[0.98$, 1.22]). Based on these results, hypothesis $\mathrm{H} 3 \mathrm{~b}$ cannot be confirmed. We hypothesized that children experiencing a parental separation growing up with only a biological father would show the highest level of juvenile delinquency, and children born to a single parent growing up with only a biological mother would show the lowest level of juvenile delinquency (H3b). However, our results showed that children born to a single parent growing up with only a biological mother showed the highest likelihood on becoming a suspect of juvenile delinquency, and children born to a single parent growing up with only a biological father showed the lowest likelihood on becoming a suspect of juvenile delinquency.

\section{Sex of the Biological Parent and the Child in Single-Parent Families}

A logistic regression was performed to establish the relation between the sex of the biological parent in combination with the sex of the child in the single-parent family and juvenile delinquency, and compared children in each category to daughters living with both biological parents (the reference category, see Table 3). Note that the estimates reported in Table 3 (and in the other regression result tables) allow us to compare the effects of any two categories by taking the ratio of their odds ratios. This feature allows for more meaningful interpretations. In addition, we calculated confidence intervals of these odds ratios.

A daughter growing up with only a biological mother $(\mathrm{OR}=2.00,95 \% \mathrm{CI}[1.95$, $2.05])$ or only a biological father $(\mathrm{OR}=1.79,95 \% \mathrm{CI}[1.66,1.93])$ significantly increased the chance that the daughter became a suspect of delinquent behavior compared to a daughter growing up with both biological parents. A daughter growing up with a biological mother in comparison with a biological father also significantly increased the chance that the daughter became a suspect of delinquent behavior $(2.00 / 1.79=1.12,95 \% \mathrm{CI}[1.03,1.20])$. A son growing up with only a biological mother $(\mathrm{OR}=1.62,95 \% \mathrm{CI}[1.58,1.65])$ or only a biological father (OR $=1.41,95 \%$ CI $[1.34,1.48])$ significantly increased the chance that the son became a suspect of delinquent behavior compared to a son growing up with both biological parents. A son growing up with a biological mother in comparison with a biological father also significantly increased the chance that the son became a suspect of delinquent behavior $(\mathrm{OR}=5.58 / 4.85=1.15,95 \% \mathrm{CI}[1.09,1.21])$. This means that hypothesis $\mathrm{H} 3 \mathrm{~d}$ is only partially confirmed, because sons growing up with biological mothers (compared to sons growing up with biological fathers) did show a higher likelihood to engage in juvenile delinquency. However, daughters growing up with biological mothers (compared to daughters growing up with biological fathers) also showed an increased likelihood to engage in juvenile delinquency. ${ }^{5}$

\footnotetext{
5 As an exploratory analysis, we also performed a logistic regression to establish the relation between the sex of the parent in combination with the sex of the child in the three different single-parent families and juvenile delinquency (thus combining the same-sex hypothesis and the family crisis model) and compare this to daughters living with both parents (see Table 9A in the Appendix). A daughter growing up with only a mother when the daughter is born to a single parent compared to growing up with only a father when the daughter is born to a single parent, significantly increased the chance that the daughter
} 


\section{Control Variables}

Most of the estimates for the control variables included in all models were in line with expectations from the literature (see Appendix for all tables comprising the results including the control variables). Having one or two criminal biological parents, being a boy, coming from a later birth cohort, having one or two stepparents, and having at least one biological parent from a Western or non-Western country, all increased the likelihood that the child has been a suspect of a criminal act. We found no effect of household income on children's likelihood to engage in juvenile delinquency. Children born to a biological mother before age 20 or children born to a biological mother aged 20 to 29 were more likely to become a suspect of juvenile delinquency than children born to a biological mother aged 30 to 39 . Children having an older biological mother (age 40 or older) when they were born also showed a higher level of juvenile delinquency than children born to a biological mother aged 30 to 39 .

Both household income and the presence of stepparents could possibly mediate the relation between family composition and delinquency. ${ }^{6}$ Therefore, we also performed all analyses of this study without including these two variables, so that the family composition variables capture both direct and indirect effects. Removing these two variables did not change the directions or significance levels of the remaining variables. Consequently, we include household income and the presence of stepparents in the reported outcomes.

\section{Discussion}

By analyzing longitudinal population register data from of the Netherlands, the current study sought to expand existing knowledge on the relationship between growing up in single-parent families and delinquency during adolescence (ages 12-18). Single-parent families were differentiated along three dimensions, namely (1) by how they were constituted (either parental separation, parental decease, or being born to a single parent), (2) by the age of the child when the single-parent family was constituted, and (3) by the sex of the biological parent the child grew up with in the single-parent family. See Table 4 for an overview of the hypotheses and findings in this study.

\section{Footnote 5 (continued)}

became a suspect of delinquent behavior. No parental sex differences were found when daughters experienced a parental separation or a parental death. A son growing up with only a mother when the son is born to a single parent compared to growing up with only a father when the son is born to a single parent, significantly increased the chance that the son became a suspect of delinquent behavior. Moreover, a son growing up with only a mother due to a parental separation compared to growing up with only a father due to a parental separation, significantly increased the chance that the son became a suspect of delinquent behavior. No parental sex differences were found when sons experienced a parental death.

${ }^{6}$ We thank one of the anonymous reviewers for this observation. 
First, based on extensive prior evidence (e.g., Kroese et al., 2021), we hypothesized that growing up in a single-parent family would increase the likelihood of engaging in juvenile delinquency, as compared to growing up with both biological parents (H1a). Our results confirmed this hypothesis, showing that having lived with only one biological parent before age 12 increased the likelihood that an adolescent became involved in crime during adolescence.

Second, based on the family crisis model, we hypothesized that, of the three categories of children growing up in a single-parent family, those who experienced a parental separation would display the highest level of juvenile delinquency, followed by those who experienced a parental death. Children born to a single parent were hypothesized to display the lowest levels (H1b). However, children born to a single parent showed the highest level of delinquency. Children who experienced parental separation and children having one deceased biological parent both showed lower levels of delinquency. This is in contrast with the family crisis model. A possible explanation of this finding is that the three categories of single-parent families are confounded with the length of exposure: While children born to a single parent have been exposed their whole life to a single-parent family when they reach adolescence, children experiencing parental separation or decease are on average exposed for a much shorter time period (which is congruent to the results of hypothesis 2). Since children born to a single parent never lived with two biological parents, this might result in a higher risk of juvenile delinquency. Moreover, we did not find the expected difference in delinquency between children who experienced parental separation and children having one deceased biological parent. Since a study by Juby and Farrington (2001) found contradictory results depending on the method used to investigate the differences between parental separation and parental death, and a recent study by Berg et al. (2019) found an increased risk of violent crime after experiencing a parental death, it is possible that the family crisis model is not valid, or is no longer valid.

Third, we hypothesized that a lower age of the children during the constitution of the single-parent family would increase the likelihood to engage in juvenile delinquency (H2a). Our results confirmed that a lower age during the start of a singleparent family increased the chance that the child has been a suspect of a criminal act during adolescence. This is exactly in line with Bowlby's attachment theory (Ainsworth \& Bowlby, 1991) that suggests that disruptions at younger ages (especially during the first 5 years of life) are more damaging than disruptions at a later age, and in line with the study conducted by Juby and Farrington (2001), reporting a higher risk of juvenile delinquency when the disruption occurred from 0 to 4 years old. Again, as described above, this could also be influenced by the length of exposure of the child to the single-parent family. Next to this, the likelihood to engage in juvenile delinquency at a higher age of the children during the start of a single-parent family is also substantially higher compared to children growing up with two biological parents.

Fourth, we hypothesized that children experiencing a parental separation at a younger age show a higher level of juvenile delinquency, compared to children experiencing a parental death at a younger age (H2b). This hypothesis was rejected, because children experiencing a parental separation at a younger age and children 


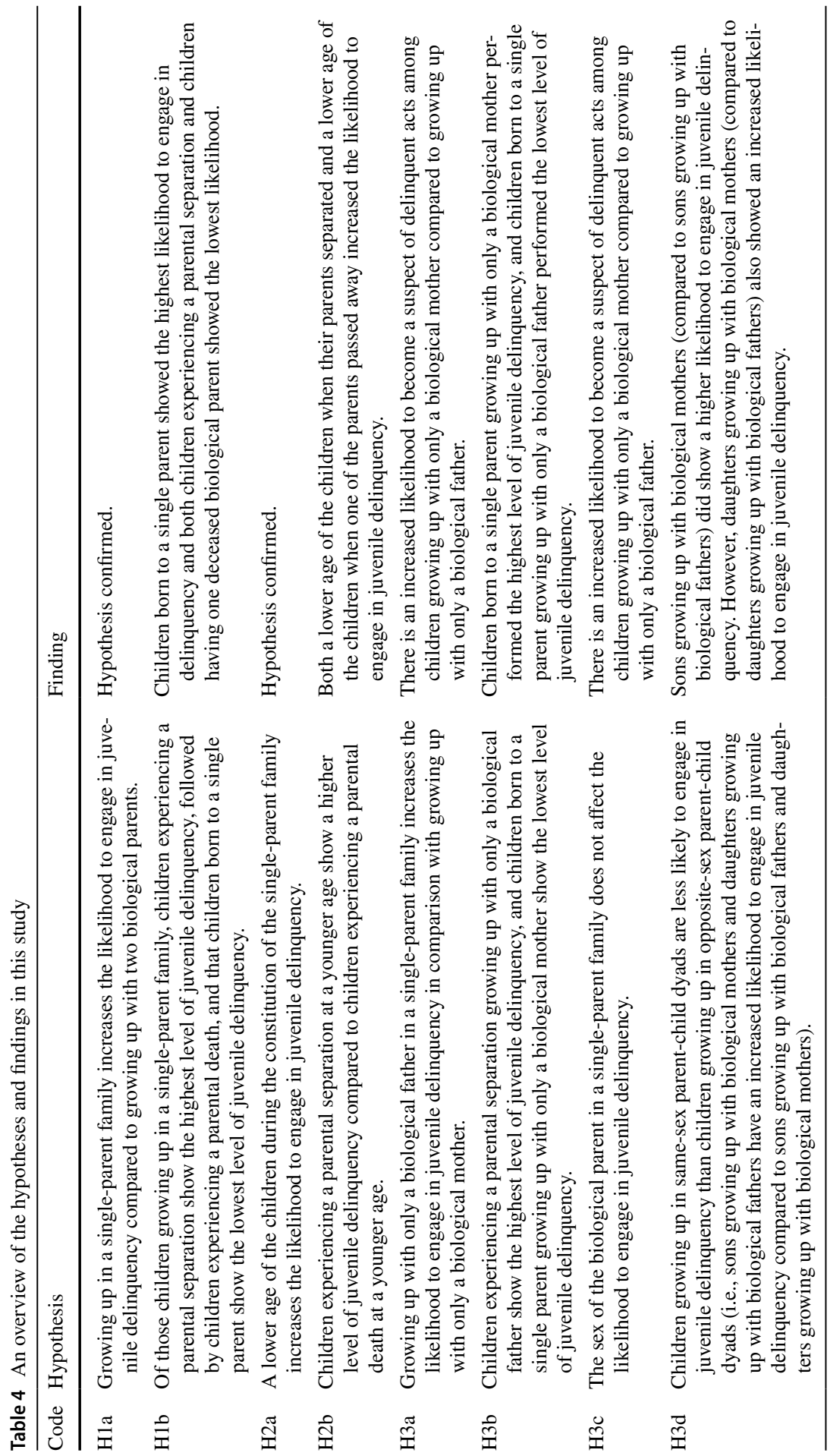


experiencing a parental death at a younger age both show a higher level of juvenile delinquency, compared to experiencing the start of both types of single-parent families at a higher age. This is in line with Bowlby's attachment theory, but not with the family crisis model, since we did not find a difference between the two types of single-parent families. It is also in line with previous results described above: we did find age effects at the start of the single-parent family, but no effects of the type of single-parent family. Therefore, the findings confirm our thoughts of the importance of the length of exposure to the single-parent family, since all three types of single-parent families show a higher likelihood to engage in juvenile delinquency after experiencing the start at a younger age than at an older age.

Fifth, we hypothesized that growing up with only a biological father compared to only a biological mother in a single-parent family would increase the likelihood to engage in juvenile delinquency $(\mathrm{H} 3 \mathrm{a})$, and we hypothesized that the sex of the biological parent in a single-parent family would not affect the likelihood to engage in juvenile delinquency (H3c). However, contrasting Bowlby's attachment theory, the maternal hypothesis, and the equality hypothesis, our results suggested that growing up with only a biological mother significantly increased the chance that the child has been a suspect of a criminal act. Since we controlled for many variables in our analyses, for instance, a lower household income in single-mother families or a higher occurrence of a new stepparent in single-parent families cannot explain our unexpected results. One possible explanation that cannot be tested with population register data is parental closeness. Research on the roles of mothers and fathers in causing delinquency has shown that children are closer to their mother than to their father, but closeness to the father is the better predictor of delinquent behavior (Johnson, 1987). Moreover, a better father-child relationship was related to a deeper decline trajectory of adolescent delinquency (Yoder et al., 2016). Therefore, higher paternal closeness might be related to the children in single-father families, decreasing the likelihood to engage in juvenile delinquency.

Sixth, we hypothesized that children experiencing a parental separation growing up with only a biological father would show the highest level of juvenile delinquency, and children born to a single parent growing up with only a biological mother would show the lowest level of juvenile delinquency (H3b). However, our results showed that children born to a single parent growing up with only a biological father showed the lowest level of juvenile delinquency, and children born to a single parent growing up with only a biological mother showed the highest level of juvenile delinquency. Factors that otherwise could have been a possible explanation for this finding have already been controlled for in the analysis (e.g., household income, age of the mother, and stepparents).

Seventh, we hypothesized that the sex of the biological parent in a single-parent family would depend on the sex of the child to increase the likelihood to engage in juvenile delinquency (H3d). This hypothesis is only partially confirmed, because sons growing up with biological mothers (compared to sons growing up with biological fathers) did show a higher likelihood to engage in juvenile delinquency. However, daughters growing up with biological mothers (compared to daughters growing up with biological fathers) also showed an increased likelihood to engage in juvenile delinquency, although we expected to find the opposite result. Again, as 
mentioned above, this might be explained by paternal closeness, since both sons and daughters show a lower likelihood to engage in juvenile delinquency when the closeness to their father is high (Johnson, 1987; Yoder et al., 2016), most likely also occurring in single-father families. Another possible explanation is that sons are more in need of a role model of the same gender than daughters. These two explanations are hypothetical and require further exploration.

\section{Limitations and Future Research}

Although using population register data has many advantages (such as having a large sample size and data provided by reliable sources), it also has some limitations. First, register data do not include information on the mechanisms of family life during childhood that are potentially relevant. For example, the level of parental conflict before and after the parental separation has been shown to increase the problem behaviors of the children (Amato \& Cheadle, 2008). This lack of data on prior family dynamics may be an important source of residual confounding. Second, we cannot extract the full information from the data about the living situation of the families. The children can be registered at only one address in the Dutch population register, yet other types of living situations are possible as well. For instance, after a parental separation, the children can be officially registered at their mothers' address, but unofficially live with their biological father $50 \%$ of the time as well. These type of co-parenting arrangements cannot be studied, which is unfortunate as an increasing proportion of separated parents in Western countries now have coparenting arrangements in place (Smyth, 2017). This situation also applies to the biological parents, since it is possible that they have an intimate relationship but live at separate addresses (i.e., Living Apart Together relationship), wanted or unwanted (e.g., due to living away from home for work or due to imprisonment). Third, population register data only uses officially registered information regarding delinquency, while not all delinquent acts are registered by the police, resulting in an underestimation of the number of delinquent behaviors (Groot et al., 2007).

We have three suggestions for future research. First, new studies should examine juvenile delinquency in more detail, including a more detailed distinction between incidental and persistent delinquency, the difference between minor and serious crime, and different types of crime. For instance, because the household income is generally lower in families with only one biological parent, it is possible that the children are more inclined to engage in offenses such as stealing to obtain money. Second, our study did not make a distinction between temporary parental separations and permanent parental separations. It is possible that the separated biological parents reunite after a (couple of) year(s). Although a child in our study is categorized as having experienced a parental separation, which is correct, it would be great to take into account in future research whether the parents permanently separated, reunited before age 12 of the child, or reunited during the child's adolescent years. Third, to this day, many children still grow up in single-parent families, and growing up in a single-parent family still seems to have negative consequences. Thus, for instance, this seems not to be just a consequence of stigma, because if stigma 
played a major role, the effects would be relatively minor by now. Therefore, we recommend investigating the mechanisms behind the relation between single-parent families and juvenile delinquency.

\section{Implications}

The methodological implication of our research is that this topic regarding family structure and juvenile delinquency could be investigated more extensively with population register data. Because some family structures are relatively rare, such as children living in single-father families and children being born into a single-parent family, researchers had problems with finding enough respondents for their studies (Demuth \& Brown, 2004). In contrast with the hypothesis regarding age of the child at the start of the family (with results in line with Bowlby's attachment theory), the hypotheses about the differences between single-parent families (based on the family crisis model) and the sex of the parent whom the children live with (based on Bowlby's attachment theory, the maternal hypothesis, the equality hypothesis, and the same-sex hypothesis) were not confirmed. Since researchers were able to study the effects of age at the start of the single-parent family, it is not surprising that Bowlby's attachment theory, previous studies (e.g., Juby \& Farrington, 2001), and our study show similar results. The other hypotheses about how the differences between single-parent families and the sex of the parent the children live with are related to juvenile delinquency, resulted in mixed outcomes with regard to theories, previous studies, and the present study. Therefore, and aware of the fact that availability of such data for scientific research varies widely between countries, we recommend using population register data more often to study the relation between single-parent families and juvenile delinquency, to obtain more knowledge about the validity of these theories.

Our results potentially also have theoretical implications. We clearly found evidence for the criminological theories (e.g., general strain theory and social control theory; Agnew, 2006; Hirschi, 1969) stating that growing up in a single-parent family and juvenile delinquency are related. However, as described above, we found mixed results with regard to some of the other theories. Based on the family crisis model, we expected to find that children experiencing a parental separation would show the highest level of juvenile delinquency, followed by children experiencing a parental death, and that children born to a single parent would show the lowest level of juvenile delinquency. However, both children experiencing a parental separation and children having one deceased biological parent showed a similar likelihood to engage in juvenile delinquency. This may be caused by the change toward increasingly tolerant attitudes and norms regarding singleparent families in Western countries (Kreidl et al., 2017) and the promotion of shared parenting (Richtlijnen Jeugdhulp, 2020), resulting in a reduced likelihood to engage in delinquency over the last couple of decades for children who experienced a parental separation. Moreover, children born to a single parent showed the highest likelihood to engage in delinquency. Therefore, it is possible that the family crisis model is not valid, or is no longer valid, since the children who did 
not experience a crisis event showed the highest level of juvenile delinquency. Our results also showed that disruptions at younger ages are more damaging than disruptions at a later age (in line with Bowlby's attachment theory). However, when looking at the sex of the parent, our results showed that children born to a single parent growing up with only a biological father performed the lowest level of juvenile delinquency. This would imply that the sex of the parent is a stronger predictor of juvenile delinquency than the age of the child during the disruption. We indeed found an increased likelihood to become a suspect of delinquent acts among children growing up with only a biological mother compared to growing up with only a biological father. This is in contrast with all theories mentioned regarding the sex of the single parent combined with juvenile delinquency (Bowlby's attachment theory, the maternal hypothesis, the equality hypothesis, and the same-sex hypothesis). However, although our results indeed showed a statistically significant difference between single fathers and single mothers, these differences are rather small (i.e., this is an enormous dataset and tiny associations observed will often be significant), and we found no gender differences for children experiencing a parental separation and children having one deceased biological parent when specifically looking at the type of single-parent family. Concluding, except for the criminological theories stating that growing up in a single-parent family and juvenile delinquency are related, we found unexpected results with regard to other theories mentioned. More research is warranted on this topic for an unequivocal answer with regard to our unexpected results, as well as to be able to provide recommendations for practice and policy.

\section{Conclusion}

Compared to children living with both biological parents, findings suggest that the likelihood of juvenile delinquency increases (1) when children are born to a single parent, followed by children with separated parents and children experiencing parental death, (2) when the single-parent family started at a younger age, and (3) when children grow up with only a biological mother, both for sons and daughters, compared to only a biological father. This implies that the relationship between growing up in single-parent families and juvenile delinquency is much more complex than often assumed. Future research should pay more attention to diversity in the composition of single-parent families.

Supplementary Information The online version contains supplementary material available at https://oi. org/10.1007/s40865-021-00183-7.

Acknowledgements We want to thank Anne-Rigt Poortman and other participants of the Marie Jahoda Summer School of Sociology for their feedback on an earlier version of this article.

Funding Financial support was provided by the Amsterdam Law and Behavior Institute (A-LAB), the Netherlands Institute for the Study of Crime and Law Enforcement (NSCR), and the Open Data Infrastructure for Social Science and Economic Innovations (ODISSEI). 
Open Access This article is licensed under a Creative Commons Attribution 4.0 International License, which permits use, sharing, adaptation, distribution and reproduction in any medium or format, as long as you give appropriate credit to the original author(s) and the source, provide a link to the Creative Commons licence, and indicate if changes were made. The images or other third party material in this article are included in the article's Creative Commons licence, unless indicated otherwise in a credit line to the material. If material is not included in the article's Creative Commons licence and your intended use is not permitted by statutory regulation or exceeds the permitted use, you will need to obtain permission directly from the copyright holder. To view a copy of this licence, visit http://creativecommons.org/licen ses/by/4.0/.

\section{References}

Agnew, R. (2006). General strain theory: Current status and directions for further research. Taking stock: The status of criminological theory, 15, 101-123. https://doi.org/10.4324/9781315130620-4

Ainsworth, M. D. S., \& Bowlby, J. (1991). An ethological approach to personality development. American Psychologist, 46(4), 331-341. https://doi.org/10.1037/0003-066X.46.4.333

Amato, P. R. (2001). Children of divorce in the 1990s: An update of the Amato and Keith (1991) metaanalysis. Journal of Family Psychology, 15(3), 355. https://doi.org/10.1037//0893-3200.15.3.355

Amato, P. R., \& Cheadle, J. E. (2008). Parental divorce, marital conflict and children's behavior problems: A comparison of adopted and biological children. Social Forces, 86(3), 1139-1161. https:// doi.org/10.1353/sof.0.0025

Apel, R., \& Sweeten, G. (2010). The impact of incarceration on employment during the transition to adulthood. Social Problems, 57(3), 448-479. https://doi.org/10.1525/sp.2010.57.3.448

Becker, H. (1963). Outsiders: Studies in the sociology of deviance. Free Press.

Berg, L., Rostila, M., Arat, A., \& Hjern, A. (2019). Parental death during childhood and violent crime in late adolescence to early adulthood: a Swedish national cohort study. Palgrave Communications, 5(1), 1-8. https://doi.org/10.1057/s41599-019-0285-y

Besemer, S., Ahmad, S. I., Hinshaw, S. P., \& Farrington, D. P. (2017). A systematic review and metaanalysis of the intergenerational transmission of criminal behavior. Aggression and Violent Behavior, 37, 161-178. https://doi.org/10.1016/j.avb.2017.10.004

Besjes, G., \& Van Gaalen, R. (2008, July 7). Jong geleerd, fout gedaan? CBS. https://www.cbs.nl/nl-nl/ nieuws/2008/28/kinderen-van-verdachten-vaker-in-de-fout

Brown, S. L. (2006). Family structure transitions and adolescent well-being. Demography, 43(3), 447461. https://doi.org/10.1353/dem.2006.0021

Campagna, L., \& Zaykowski, H. (2020). Health consequences and help-seeking among victims of crime: An examination of sex differences. International Review of Victimology, 26(2), 181-195. https://doi. org/10.1177/0269758019900392

CBS (2018). Bijna 1 op de 10 baby's wordt geboren in eenoudergezin. Retrieved January 5, 2022, from https://www.cbs.nl/nl-nl/nieuws/2018/52/bijna-1-op-de-10-baby-s-wordt-geboren-in-eenoudergezin

CBS (2019a). Bijna 1 op de 6 kinderen woont in een eenouderhuishouden. Retrieved January 5, 2022, from https://www.cbs.nl/nl-nl/nieuws/2019/52/bijna-1-op-de-6-kinderen-woont-in-een-eenouderhu ishouden

CBS (2019b). Welvaart in Nederland 2019. Retrieved January 5, 2022, from https://longreads.cbs.nl/ welvaartinnederland-2019/bijlagen/

CBS (2020). Vrouwen lopen na scheiding steeds minder risico op armoede. Retrieved January 5, 2022, from https://www.cbs.nl/nl-nl/nieuws/2020/25/vrouwen-lopen-na-scheiding-steeds-minder-risicoop-armoede

CBS (2021). Welke definitie van migratieachtergrond wordt in de barometer gehanteerd? Retrieved January 5, 2022, from https://www.cbs.nl/nl-nl/deelnemers-enquetes/deelnemers-enquetes/bedrijven/ faq/barometer-culturele-diversiteit/welke-definitie-van-migratieachtergrond-wordt-in-de-barometergehanteerd

Demuth, S., \& Brown, S. L. (2004). Family structure, family processes, and adolescent delinquency: The significance of parental absence versus parental gender. Journal of Research in Crime and Delinquency, 41(1), 58-81. https://doi.org/10.1177/0022427803256236 
Eitle, D. (2006). Parental gender, single-parent families, and delinquency: Exploring the moderating influence of race/ethnicity. Social Science Research, 35(3), 727-748. https://doi.org/10.1016/j.ssres earch.2005.06.003

Eurostat (2019). Households with children in the EU. Retrieved January 5, 2022, from https://ec.europa. eu/eurostat/web/products-eurostat-news/-/EDN-20190601-1

Farrell, G., Tilley, N., \& Tseloni, A. (2014). Why the crime drop? Crime and Justice, 43(1), 421-490. https://doi.org/10.1086/678081

Gilman, A. B., Hill, K. G., \& Hawkins, J. D. (2015). When is a youth's debt to society paid? Examining the long-term consequences of juvenile incarceration for adult functioning. Journal of Developmental and Life-Course Criminology, 1(1), 33-47. https://doi.org/10.1007/s40865-015-0002-5

Groot, I., De Hoop, T., Houkes, A., \& Sikkel, D. (2007). De kosten van criminaliteit: Een onderzoek naar de kosten van criminaliteit voor tien verschillende delicttypen. SEO Economisch Onderzoek.

Hay, C., Fortson, E. N., Hollist, D. R., Altheimer, I., \& Schaible, L. M. (2006). The impact of community disadvantage on the relationship between the family and juvenile crime. Journal of Research in Crime and Delinquency, 43(4), 326-356. https://doi.org/10.1177/0022427806291262

Hirschi, T. (1969). A control theory of delinquency. In F. P. Williams III \& M. D. McShane (Eds.), Criminology theory: Selected classic readings (pp. 289-305). Routledge.

Johnson, R. E. (1987). Mother's versus father's role in causing delinquency. Adolescence, 22(86), 305.

Juby, H., \& Farrington, D. P. (2001). Disentangling the link between disrupted families and delinquency. British Journal of Criminology, 41(1), 22-40. https://doi.org/10.1093/bjc/41.1.22

Kierkus, C., \& Baer, D. (2003). Does the relationship between family structure and delinquency vary according to circumstances? An investigation of interaction effects. Canadian Journal of Criminology and Criminal Justice, 45, 405-429. https://doi.org/10.3138/cjccj.45.4.405

Kreidl, M., Štípková, M., \& Hubatková, B. (2017). Parental separation and children's education in a comparative perspective: Does the burden disappear when separation is more common? Demographic Research, 36, 73-110. https://doi.org/10.4054/DemRes.2017.36.3

Kroese, J., Bernasco, W., Liefbroer, A. C., \& Rouwendal, J. (2021). Growing up in single-parent families and the criminal involvement of adolescents: A systematic review. Psychology, Crime \& Law, 27(1), 61-75. https://doi.org/10.1080/1068316X.2020.1774589

Larmuseau, M. H., Claerhout, S., Gruyters, L., Nivelle, K., Vandenbosch, M., Peeters, A., van den Berg, P., Wenseleers, T., \& Decorte, R. (2017). Genetic-genealogy approach reveals low rate of extrapair paternity in historical Dutch populations. American Journal of Human Biology, 29(6), e23046. https://doi.org/10.1002/ajhb.23046

Mack, K. Y., Leiber, M. J., Featherstone, R. A., \& Monserud, M. A. (2007). Reassessing the familydelinquency association: Do family type, family processes, and economic factors make a difference? Journal of Criminal Justice, 35(1), 51-67. https://doi.org/10.1016/j.jcrimjus.2006.11.015.

Massoglia, M. (2008). Incarceration as exposure: the prison, infectious disease, and other stress-related illnesses. Journal of Health and Social Behavior, 49(1), 56-71. https://doi.org/10.1177/0022146508 04900105

Messerschmidt, J. W. (2013). Crime as structured action: On the intersection of masculinities, race, class, sexuality, and crime. Rowman \& Littlefield Publishers, Inc.

Peterson, D., Esbensen, F. A., Taylor, T. J., \& Freng, A. (2007). Youth violence in context: The roles of sex, race, and community in offending. Youth Violence and Juvenile Justice, 5(4), 385-410. https:// doi.org/10.1177/1541204006297369

Pew Research Center (2019). U.S. has world's highest rate of children living in single-parent households. Retrieved January 5, 2022, from https://www.pewresearch.org/fact-tank/2019/12/12/u-s-childrenmore-likely-than-children-in-other-countries-to-live-with-just-one-parent/

Pogarsky, G., Lizotte, A. J., \& Thornberry, T. P. (2003). The delinquency of children born to young mothers: Results from the Rochester Youth Development Study. Criminology, 41(4), 1249-1286. https:// doi.org/10.1111/j.1745-9125.2003.tb01019.x

Price, C., \& Kunz, J. (2003). Rethinking the paradigm of juvenile delinquency as related to divorce. Journal of Divorce \& Remarriage, 39(1-2), 109-133. https://doi.org/10.1300/J087v39n01_07

Ram, B., \& Hou, F. (2005). Sex differences in the effects of family structure on children's aggressive behavior. Journal of Comparative Family Studies, 36(2), 329-341. https://doi.org/10.1111/jomf. 12456

Richtlijnen Jeugdhulp (2020). Algemene adviezen naar leeftijd van de jeugdigen. Retrieved January 5 , 2022, from: https://richtlijnenjeugdhulp.nl/scheiding/interventies-voor-jeugdigen-met-gescheidenouders/algemene-adviezen-naar-leeftijd-van-de-jeugdigen/ 
Rima, D., Yerbol, A., Batyrbek, S., Orynbassar, T., \& Beaver, K. M. (2019). Examining the potential association between immigration and criminal involvement using a nationally representative and longitudinal sample of youth. Journal of Interpersonal Violence. https://doi.org/10.1177/08862 60519888531

Smyth, B. M. (2017). Special issue on shared-time parenting after separation. Family Court Review, 55(4), 494-499.

Sogar, C. (2017). The influence of family process and structure on delinquency in adolescence-An examination of theory and research. Journal of Human Behavior in the Social Environment, 27(3), 206-214. https://doi.org/10.1080/10911359.2016.1270870

Spohn, R. E., \& Kurtz, D. L. (2011). Family structure as a social context for family conflict: Unjust strain and serious delinquency. Criminal Justice Review, 36(3), 332-356. https://doi.org/10.1177/07340 16811402495

Staatsblad. (1995). 240. SDU uitgevers.

Staatsblad. (1997). 507. SDU uitgevers.

Van der Wiel, R., \& Kooiman, N. (2019). Children of separated parents: Registered versus reported place of residence. Retrieved January 5, 2022, from https://www.cbs.nl/-/media/_pdf/2019/24/2019ep12children-of-separated-parents.pdf

Vanassche, S., Sodermans, A., Matthijs, K., \& Swicegood, G. (2014). The effects of family type, family relationships and parental role models on delinquency and alcohol use among Flemish adolescents. Journal of Child and Family Studies, 23(1), 128-143. https://doi.org/10.1007/s10826-012-9699-5

Yoder, J. R., Brisson, D., \& Lopez, A. (2016). Moving beyond fatherhood involvement: The association between father-child relationship quality and youth delinquency trajectories. Family Relations, 65(3), 462-476. https://doi.org/10.1111/fare.12197

Publisher's Note Springer Nature remains neutral with regard to jurisdictional claims in published maps and institutional affiliations.

\section{Authors and Affiliations}

\section{Janique Kroese ${ }^{1,2}$ (D) Wim Bernasco ${ }^{1,2}$ (D) Aart C. Liefbroer ${ }^{3,4,5}$ (D) Jan Rouwendal ${ }^{1,6}$}

1 Department of Spatial Economics, Vrije Universiteit Amsterdam, De Boelelaan 1105, $1081 \mathrm{HV}$ Amsterdam, the Netherlands

2 Netherlands Institute for the Study of Crime and Law Enforcement (NSCR), De Boelelaan 1077, 1081 HV Amsterdam, the Netherlands

3 Netherlands Interdisciplinary Demographic Institute (NIDI-KNAW), Lange Houtstraat 19, 2511 CV The Hague, the Netherlands

4 Department of Epidemiology, University Medical Center Groningen, University of Groningen, Hanzeplein 1, 9713 GZ Groningen, the Netherlands

5 Department of Sociology, Vrije Universiteit Amsterdam, De Boelelaan 1105, 1081 HV Amsterdam, the Netherlands

6 Tinbergen Institute, Gustav Mahlerplein 117, 1082 MS Amsterdam, the Netherlands 